\title{
Aproximación a los paisajes culturales del regadío. La Geria de Lanzarote
}

\author{
Jordi Sardà Ferran y Antonio Zamora Cabrera \\ Universitat Politècnica de Catalunya \\ sardaprim15@gmail.com,azcab@hotmail.com
}

\begin{abstract}
Resumen. La Geria de Lanzarote explica -a nuestro entender- la agricultura como el trabajo inteligente de la tierra. La geometría de "pequeños volcanes", construida con las manos, hace que las rocas protejan de los Alisios perennes las tres escasas cepas de malvasía escondidas en cada cráter, recubierto de "picón”, el lapilli volcánico. Sólo así pueden recoger el leve rocío del Atlántico, que permite a las raíces atravesar las capas ligeras de las lavas y alcanzar los suelos arcillosos más solventes y evitar, de paso, la evotranspiración. Es notoria la fotogenia del espacio conseguido, tanto como la capacidad para producir con un solo sistema - casi un solo gesto - un paisaje tan propio como insólito, que le confiere especial identidad y caracteriza la isla.

La Geria es el máximo exponente de la arquitectura agrícola insular, ejemplo de perfecta integración entre el hombre y la naturaleza, y muestra original de la técnica del enarenado con la que se cultiva la mayor parte de la superficie insular. Así, el hombre, en su lucha por la supervivencia en un ambiente tan hostil como Lanzarote, muestra cómo construir entornos cargados de humanidad disipando la menor energía y participando, a su vez, del carácter estético y emocional de la isla.
\end{abstract}

Palabras clave: Paisaje, agricultura, agua

Abstract. La Geria of Lanzarote explains - to our knowledge - the agriculture as a smart way to working the land. The geometry of "small volcanoes" built by hand, causes the rocks to protect from the perennial Trade Winds the few malmsey vines hidden in each crater, which are covered with "picón" (term use in the island for volcanic lapilli). Only then, the vines can pick up the slight spray of the Atlantic, allowing the roots through the thin layers of lava to reach the most solvent clay soils, and avoid in this process the evapotranspiration. Is notoriously photogenic the space achieved, as well as the ability to produce a single system - almost in a single gesture - a landscape as unusual as it is appropriate, which gives special identity and characterizes the island.

La Geria is the epitome of the island agricultural architecture, example of perfect integration between man and nature, and an original sample of the sanding technique with which the vast majority of the island's surface is cultivated. Therefore, man in his struggle for survival in a hostile environment such as Lanzarote, shows how to construct settings charged with humanity, dissipating less energy and participating, in turn, in the aesthetic and emotional character of the island environments.

Keywords: Landscape, agriculture, water

\section{Contextualización de Lanzarote y la Geria}

A día de hoy, Lanzarote es una isla pujante cuya principal actividad es el turismo. Sin embargo, tradicionalmente ha sido un territorio inhóspito y pobre, carente de agua y con una economía de subsistencia basada en la pesca y la agricultura. Debe su actual éxito y su buena reputación al particular modelo territorial implantado en los años sesenta por el artista César Manrique y el entonces presidente del Cabildo, José Ramírez. Juntos encabezan una propuesta que mezcla arte y turismo, y que tiene en el paisaje insular el principal argumento para su expansión. Éste es sin duda el principal hecho diferenciador de Lanzarote con respecto a las otras islas canarias, la fuerza estética que transmiten sus volcanes y lavas petrificadas, su arquitectura vernacular o su particular agricultura donde la Geria es, sin discusión, el principal referente.

Así, antes de abordar este espacio, se hace imprescindible trazar algunas notas sobre Lanzarote y su paisaje que nos acerquen hacia el objeto de estudio. 


\subsection{Introducción al paisaje insular}

"Ya el haber nacido en esta quemada geología de cenizas, en el medio del Atlántico, condiciona cualquier ser medianamente sensible. Toda la influencia que supone este escenario que ha rodeado mi infancia se ba manifestado sucesivamente en toda mi plástica, con gran libertad de expresión, como la misma y brutal superficie de la isla.

La última razón, y creo la que más influyó en mi amor por Lanzarote, es de indole más moral, más social e intimista, por haber conocido desde mis primeros años su gran bumildad y pobreza, en donde sus gentes tenían muchos años que emigrar por falta de lluvia y medios. Todos estos recuerdos han dejado una marca en mis sentimientos a través de los años, queriendo hacer como una revancha de demostrarme a mi mismo que no estaba equivocado con lo que pensaba podría ser esta maravillosa isla." 1

Con una superficie cercana a los $850 \mathrm{~km}^{2}$, la isla se sitúa en el extremo oriental del archipiélago canario, próxima a Fuerteventura y, aproximadamente, a $150 \mathrm{Km}$. de la costa africana. Desde el cielo se percibe como un territorio árido y extraño, punteado por numerosos volcanes, y cubierto por grandes extensiones de lava petrificada y cenizas volcánicas surcadas, estas últimas, por líneas pétreas y cientos de hoyos para la agricultura. Debe, así, su particular fisionomía a los distintos episodios eruptivos que en ella se han producido, desde los más antiguos y altos de la isla, Famara y Los Ajaches, hasta los más recientes sucedidos entre 1730 y 1736, y posteriormente, en 1824. Este último período da lugar a un área geográfica denominada las Montañas del Fuego - compuesta por una sucesión de volcanes encabezados por Timanfaya - que linda con la Geria y es causante de su particular configuración.

Por otra parte, el tipo de erupciones producidas, de origen estromboliano, se caracteriza por una primera fase explosiva donde, de forma virulenta, el volcán deyecta gases, lava y fragmentos pétreos de diversos tamaños; y una posterior de tipo efusiva, donde emana lava de forma continua. Una vez solidificado ese magma, grandes extensiones de terreno se convierten en un espacio yermo denominado localmente como Malpaís. En la isla, sus coladas llegan a ocupar aproximadamente una cuarta parte del territorio insular, sepultan terrenos agrícolas y caseríos, y suponen una nueva vuelta de tuerca a la, ya de por sí, complicada tarea de habitar en Lanzarote. Los llamados "días del fuego" (Santana, 1997) marcan así una nueva etapa que marca inexorablemente su devenir histórico conformando, a la par, un paisaje volcánico único.

En su visita a Lanzarote, la escritora británica Olivia Stone describe este espacio como

"un paisaje tremendo pero también magnifico, infernal y sugerente (...). Hay montañas por todas partes, las que se encuentran frente a nosotros son montaña de fuego por antonomasia tanto por su naturaleza como por su color (...). Las manchas de tierra de un color rojo, vivo e intenso, que contrastan con el flujo negro expelido por las entrañas de la tierra, son muy atractivas. El silencio es agobiante y terrible. Nada se mueve; no bay ni siquiera una ramita que nos indique donde sopla el viento; sólo aridez y desolación"

\footnotetext{
${ }^{1}$ Manrique (1974)

2 Arteta (2008)
} 


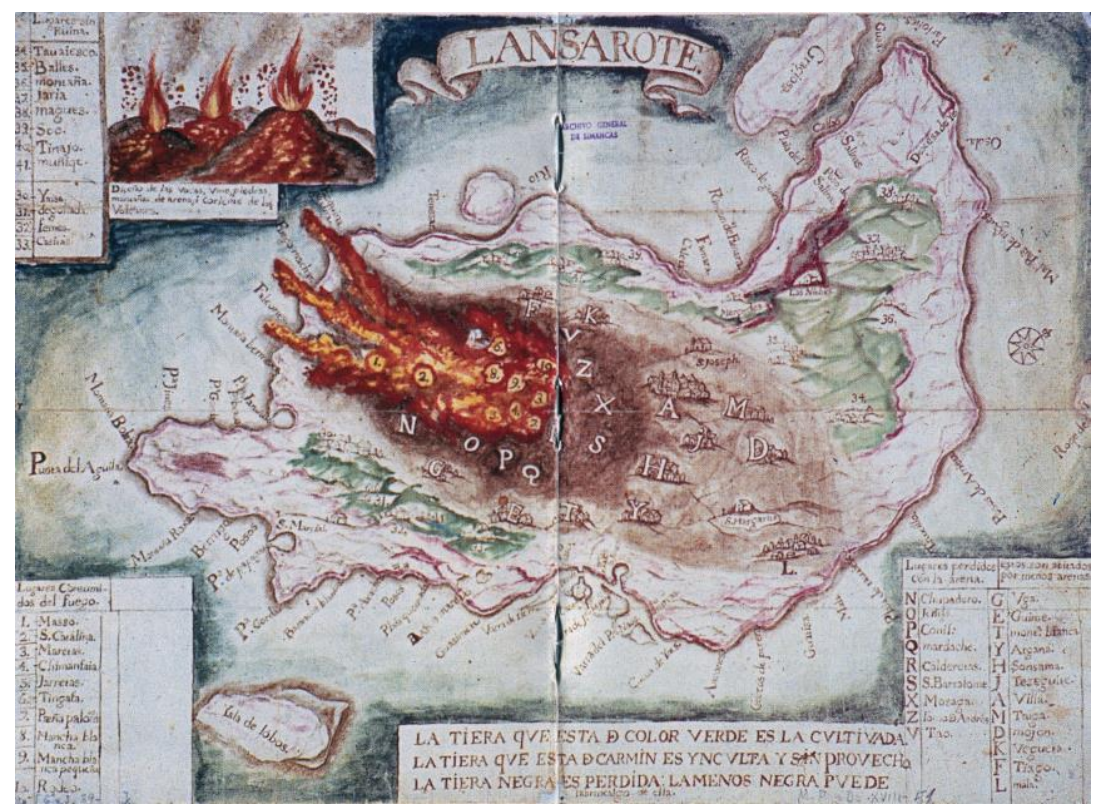

Fig. 1. Erupción de Timanfaya (Fuente: Archivo de Simancas)

La localización geográfica de Canarias y su proximidad al anticiclón de las Azores hace que las islas se vean regularmente afectadas por los Alisios, una corriente de vientos enérgicos y constantes especialmente notables en islas de escasa orografía como Lanzarote. Su presencia, además de mitigar la fuerte radiación existente, determina el paisaje insular; por un lado, siendo causante de su escasa y resistente vegetación, de porte bajo y carente de estrato arbóreo - sólo algunas especies como la palmera canaria son capaces de resistir -; como, en lo referente a la actividad humana, condicionando su arquitectura, su labor en torno a la pesca y la agricultura, y su propia manera de habitar.

"El viento de Lanzarote apuñetea el éter. Se descoyunta en el vacío. Bien quisiera árboles altos, de borrominiano ramaje... Árboles que desnudar violentamente. Tejados chinescos que destejar. Casas de balcones descolgables. Pero nada de esto tiene. Las bigueras de Ye se burlan de sus gritos dramáticos. Las casas enseñan su arquitectura simple."

La ausencia de agua es un aspecto determinante del paisaje insular. A su carencia física, se suma un clima semidesértico escaso en lluvias. En este sentido, la especial condición de Lanzarote, la más oriental del archipiélago y cercana a África, la condenan a la menor pluviometría -140 mm año- frente a los 660 de la isla de La Palma (Fernández y Pizarro, 1982).

Los términos "mareta", depósito de agua abierto, "aljibe", depósito cerrado imprescindiblemente vinculado a la casa, "pozo", hoy con aguas salinizadas, o "galería", túnel horizontal que busca y canaliza las "aguas colgadas", son una relación de conceptos, artefactos y técnicas depuradas por una práctica prolongada a fin de que el agua, siempre escasa, de la lluvia o el subsuelo, sea enteramente aprovechada por el hombre en sus diversos quehaceres.

${ }^{3}$ Espinosa, A. (1988). 
Una situación que explica mejor que ninguna otra la voluntad y capacidad de uso interno del agua en todas sus formas y posibilidades. El agua, tan escasa y rara, casi ausente, construye con la lava la memoria de Lanzarote, y determina de manera silenciosa su forma y su figura. Su aprovechamiento es parte indiscutible de la construcción material del paisaje, su uso externo, motivo de lección permanente.

El agua es el elemento más limitante para la agricultura en regiones desérticas como Lanzarote. Sin embargo, la isla es capaz de producir cultivos de forma sostenible, únicamente a través del aporte de las escasas precipitaciones, gracias a la técnica del enarenado - la Geria es su principal ejemplo - y otras variantes como las producidas en la zona del "Jable". Esta agricultura "desértica" se basa en las bondades que ejercen las cenizas volcánicas para el cultivo, entre otras, mejorar considerablemente la retención del agua en el suelo tanto en lo que se refiere a la infiltración como a la evaporación para optimizar la escasa agua de lluvia (AAVV., 2006).

En Lanzarote, si bien su "trágica belleza" (AA.VV., 1995) la diferencia claramente de las restantes islas, esta condición tan apriorísticamente favorable en la actualidad, antaño sólo conlleva escasez y miseria para sus habitantes. También, la visión estética de su paisaje ha sufrido el mismo tránsito, modificándose a lo largo de la historia desde el rechazo hasta su puesta en valor. Islas como Lanzarote o Fuerteventura, con un paisaje seco y árido alejado de los tópicos del turismo, comienzan a ser reconocidas a partir de 1930, cuando escritores y artistas como Miguel de Unamuno o Agustín Espinosa las ponen en valor. Desde entonces, Lanzarote se ha revelado como un hecho estético (Santana, 1997) fuera de los cánones tradicionales de la belleza, fruto de los estratos visibles e invisibles que conforman su paisaje, y de la acción antrópica. Las intervenciones del hombre, tanto en lo referente a las arquitecturas donde habita como en sus labores cotidianas, son ejemplo de adaptación al lugar y a los medios de que se dispone, produciendo, a la sazón, construcciones y entornos cargados de dignidad y valor estético. En su definición del paisaje lanzaroteño, Javier Maderuelo (2006), por su parte, lo sitúa entre "lo pintoresco" y "lo sublime". Identifica lo primero, en las diversas texturas y colores de sus superficies, así como en el contraste de sus arquitecturas frente a su lecho o en la ausencia de estrato arbóreo. Mientras, "lo sublime" tiene relación con la genética brutal de su naturaleza, su escala o la potencia que transmiten sus paisajes. La Geria juega un papel ambivalente en este sentido. Por un lado, resulta pintoresco su suave y ondulada orografía color negro, o ver crecer los cultivos entre las escorias del volcán; como también sublime, ver esta técnica repetirse hasta casi el horizonte, ascendiendo, incluso por las laderas de los volcanes, y relativizando la posición del hombre.

El silencio y la soledad son intrínsecos a este tipo de paisajes, al igual que otros conceptos que se relacionan con "lo sublime" como la inmensidad o el vacío. La suma de sus distintos aspectos, naturales y metafísicos, junto a una intervención humana acorde a las especificidades del territorio, parece evocar una actitud mística, propia de aquellos territorios donde emana un sentimiento de lo sagrado, de soledad y de misterio. Un lugar de signo mágico donde el hombre puede establecer vínculos con la naturaleza (Zamora, 2009) y del que César Manrique se impregna para su propuesta artística y territorial. 


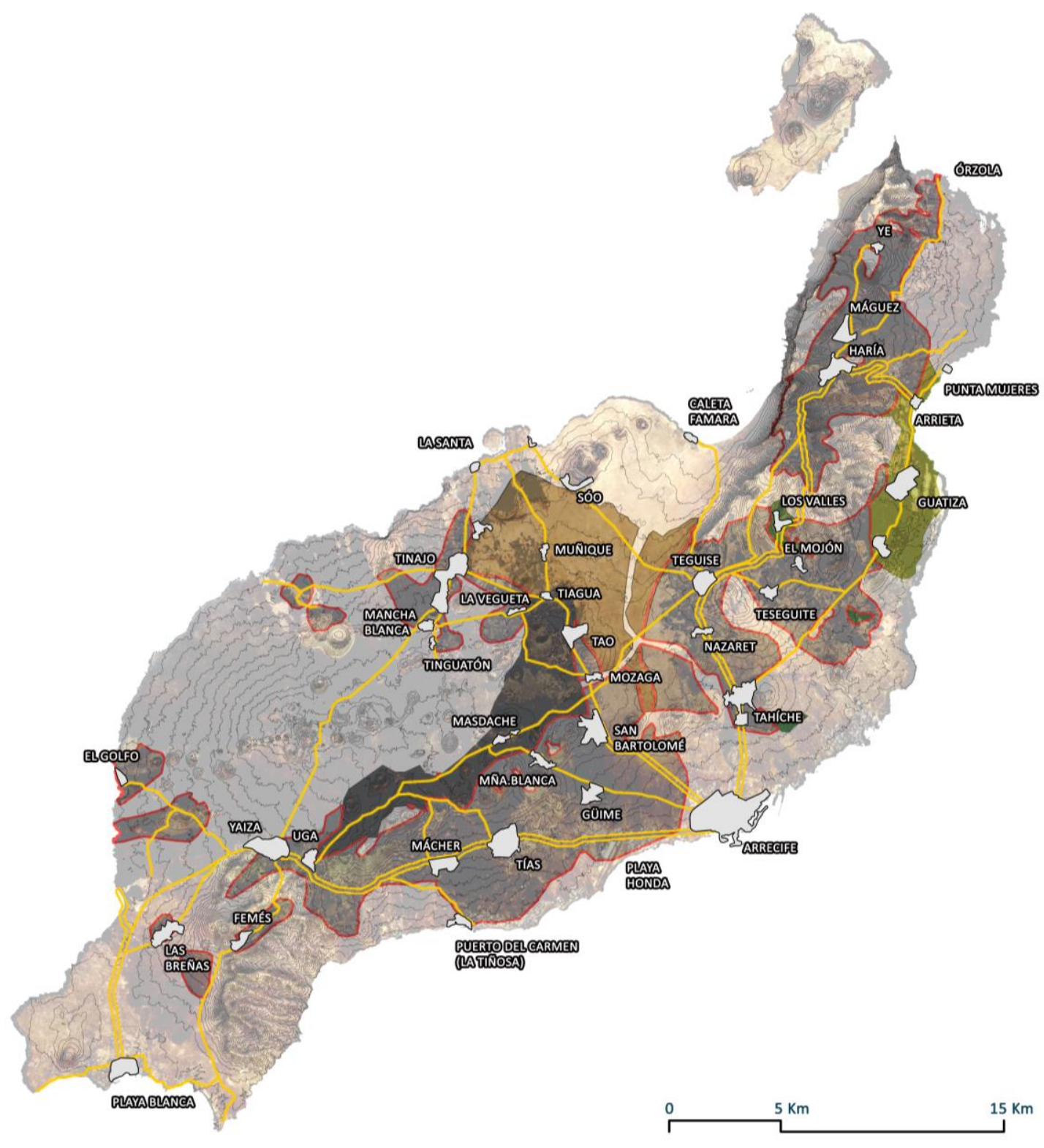

LEYENDA

\begin{tabular}{llll}
\hline & VIARIO PRINCIPAL (MEDIADOS S.XX) & & ENARENADOS NATURALES (LA GERIA) \\
\hline$\quad$ VIARIO SECUND. (MEDIADOS S.XX) & & ENARENADOS ARTIFICIALES \\
\hline NÚCLEOS URBANOS & & COCHINILLA \\
LínEAS TOPOGRÁFICAS & GAVIAS & CULTIVO EN JABLES
\end{tabular}

Fig. 2. Superficies agrícolas de Lanzarote (Autor: Antonio Zamora) 


\subsection{Agricultura y turismo, la economía insular}

La agricultura ha sido, junto a la pesca, el tradicional motor económico de la isla hasta la aparición del turismo. Dicha actividad, si bien trajo ciertos momentos de prosperidad, nunca ha sido suficiente para liberar de la miseria en la que, históricamente, habitaba su población. Entre ellos, a la desolación que produce los episodios eruptivos del siglo XVIII, le sucede una cierta etapa de florecimiento económico en el campo de la agricultura gracias a la labor y a la inteligencia del campesino. Supera esta nueva adversidad revirtiendo espacios aparentemente inertes como la Geria en terrenos aptos para el cultivo, ingeniando, para ello, una técnica única cuyo éxito se replica y generaliza en el conjunto de la isla. Este actual proceder rompe con el tradicional dominio del cereal y genera cierta prosperidad hasta comienzos del siglo XIX gracias a la introducción de nuevos cultivos como la vid, la barrilla o el nopal. Sin embargo, en un mercado tan endeble como el insular, sometido a los vaivenes locales y foráneos, esta etapa no se extiende mucho en el tiempo. Desde entonces, la actividad agrícola no sufre grandes alteraciones, permanece estancada y aletargada hasta la aparición del turismo, con una producción de subsistencia, vinculada fundamentalmente al autoabastecimiento y la exportación de ciertos productos.

La actividad turística, por su parte, no despierta hasta mediados del siglo XX. La ubicación periférica de Lanzarote, lejos de las tradicionales líneas marítimas comerciales que conectan con las capitales del archipiélago, Gran Canaria y Tenerife, hace que permanezca ausente frente a la aparición y arraigue del fenómeno turístico que en dichas islas se va produciendo desde finales del siglo XIX. Tampoco favorece a la expansión de esta actividad su régimen interno - donde existe un atraso generalizado en todos los aspectos -, ni su paisaje seco y árido, alejado de los mitos del turismo. Sin embargo, y pese a las dificultades existentes, los escasos viajeros que se acercan a Lanzarote en las primeras décadas del siglo XX comienzan, progresivamente, a valorar la estética y plasticidad de sus paisajes, y ciertos hitos naturales como las Montañas del Fuego o los Jameos del Agua. Entre estos espacios, Casto Martínez, auténtico precursor del turismo en la isla, ya destaca en 1936 la Geria como uno principales atractivos turísticos.

"Qué singulares atractivos encierran para el visitante estos inigualados paisajes, donde la Naturaleza encierra a través de tan caóticos embates, las más raras vicisitudes de transformación por que no pudo pasar territorio alguno! Y esta maravillosa atracción culmina ante el incentivo de ver surgir de entre las calcinadas escorias, llenas de vigor y lozanía, la fecunda viña, la gentil palmera, la ubérrima biguera, entre otros árboles frutales de exquisitez. no superada en país alguno. Y el viajero atónito, estupefacto, contempla, los extensos melonares, calabazares, batatares, sandieras entre inmensos tableros de vides frondosas, que surgen de las profundidades de los conos de arenas y cenizas, que en un tiempo causaron la ruina y devastación de comarcas resurgidas por el genio bumano y vueltas a la prosperidad por el soberano esfuerzo de las generaciones descendientes de los testigos del caos antaño."

Es a mediados del siglo XX cuando arraiga definitivamente la conciencia turística en la isla, aunque no es hasta la siguiente década - con la llegada de José Ramírez a la presidencia del Cabildo - cuando se comienzan a sentar las bases de la expansión turística. Entre 1960 y 1974, Ramírez y el artista César Manrique encabezan una propuesta común que sienta las bases de la exitosa actual configuración económica y territorial de Lanzarote. Implantan un modelo a escala insular que aprovecha el potencial paisajístico existente para introducir el

${ }^{4}$ Martínez (1936) 
turismo, con el objeto de rescatar la isla de la pobreza en la que habita. Su proceder supone un punto de ruptura y una novedad frente a los habituales desarrollos turísticos de la época, más preocupados por la rentabilización rápida de sus inversiones que por el paisaje que destruyen. Apuestan por un destino que combina el gusto por el "sol y playa" con una oferta complementaria basada en su particular paisaje. El patrimonio - natural y cultural se convierte en el eje sobre el que pivota la propuesta, en el que Manrique interviene aportando una nueva visión artística del paisaje en relación al turismo.

La labor del artista es capital en este punto, identificando y poniendo en valor sus principales recursos del medio natural o su arquitectura popular. Curiosamente, Lanzarote es la fuente de buena parte de su ideario artístico y, como tal, al volcarse en su faceta territorial, necesariamente incorpora a su visión turística dicho conocimiento tamizado por su filtro creativo. El paisaje impregna su arte desde su infancia, aprehendiendo de él no sólo su sentido dramático, sino también su carácter lúdico y vital. Su aprecio por la naturaleza y la cultura popular se reflejan inicialmente en la pintura, como posteriormente en las restantes facetas en las que se desenvuelve, incluida la territorial. La agricultura y los paisajes como la Geria forman parte de esa iconografía básica de Lanzarote y del artista que utiliza también para construir su propuesta territorial a partir de los sesenta. En este sentido, Manrique homenajea al agricultor con su escultura "Monumento al campesino" o "Homenaje a la fecundidad", una figura abstracta de grandes proporciones situada en el centro geográfico de la isla, y que articula distintos paisajes agrícolas de la isla como la Geria. Previamente, ya ha mostrado su interés por la agricultura en anteriores realizaciones pictóricas que sintetizan la imagen de los principales iconos de la isla.

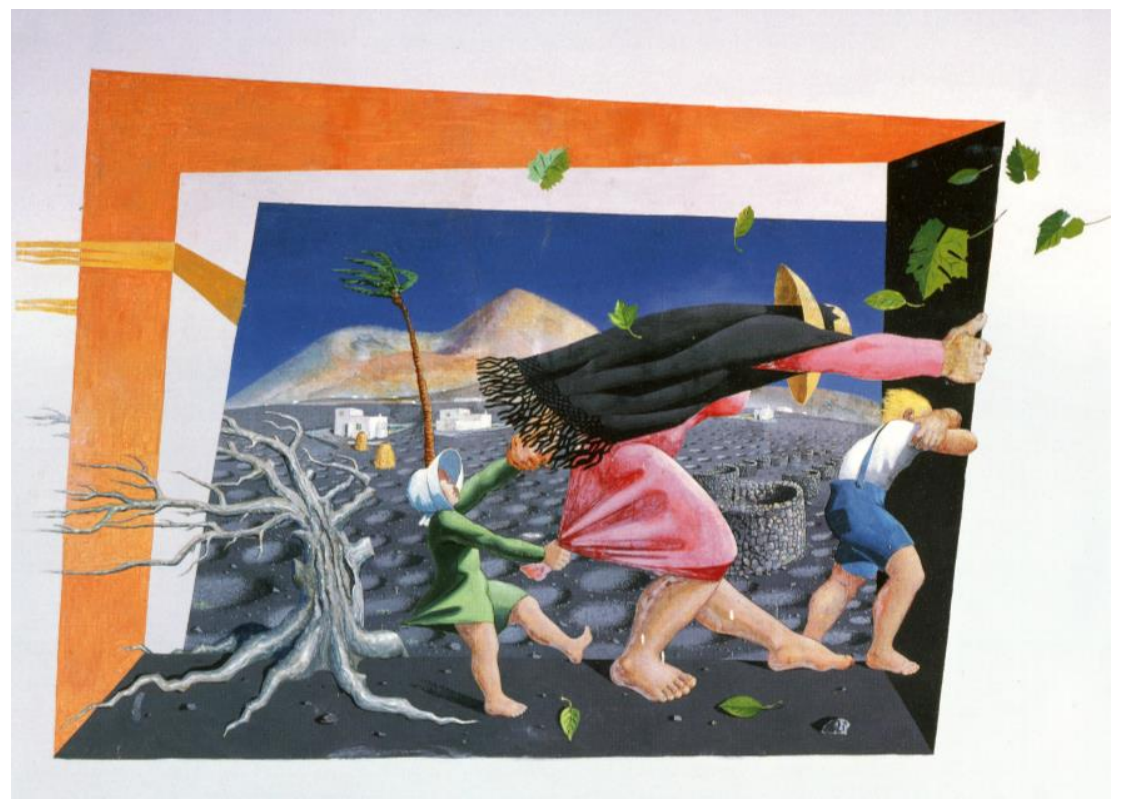

Fig. 3. Mural del Parador de Turismo de Arrecife "Viento", César Manrique, 1950 (Fuente: Maderuelo, 2006)

\section{La Geria, construcción y acción}

Es en este contexto que la Geria, entendida como encuentro de la especial geología, viento y agua, con el hombre como agente de relación y valor explica, sintetiza, a nuestro entender, el valor más profundo de la isla, su ejemplaridad procesual y su resultado formal. 


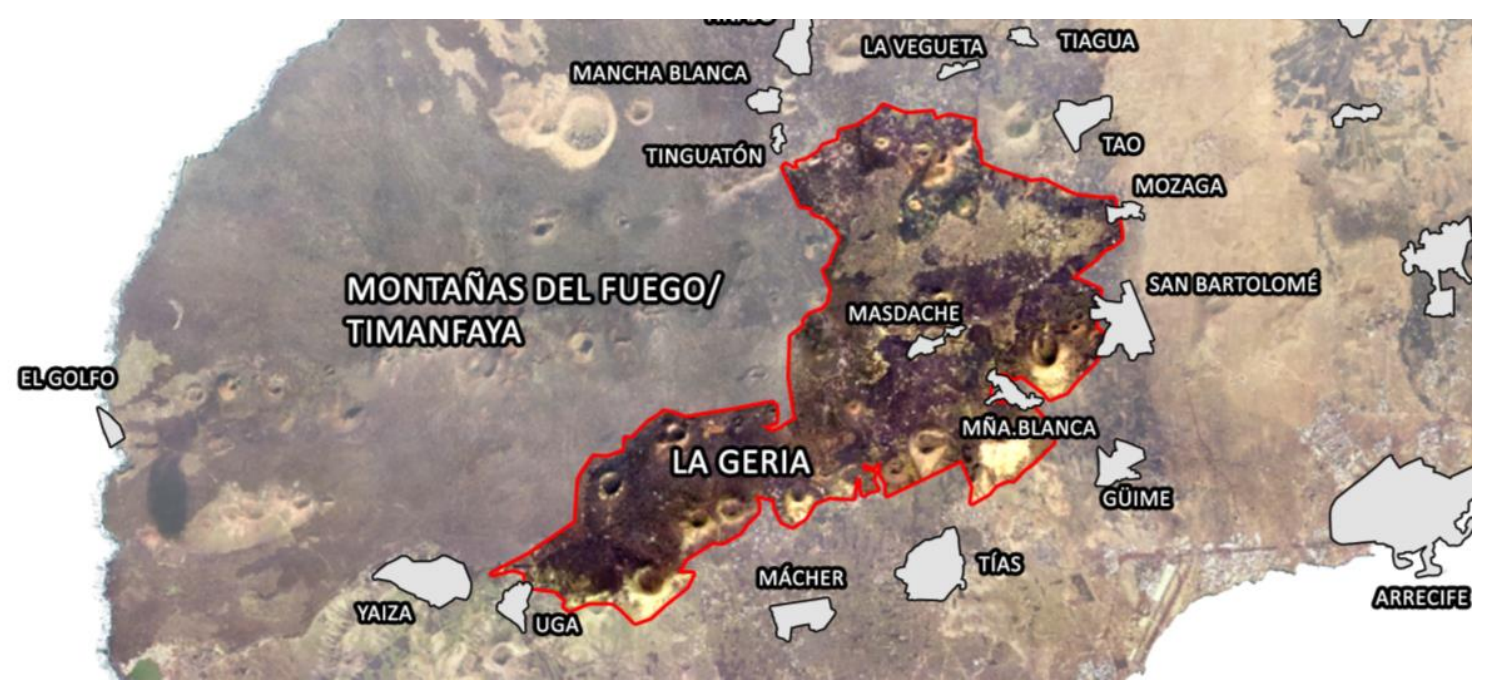

Fig. 4. Delimitación del ámbito de la Geria (Autor: Antonio Zamora)

El origen de la actual configuración de la Geria se remonta a las erupciones sucedidas en Timanfaya entre 1730 y 1736 . La catástrofe natural supone una fuerte transformación del paisaje isleño, donde buena parte de su territorio queda calcinado o sepultado por las cenizas del volcán. Sin embargo, lo que inicialmente es una tragedia para sus habitantes deviene en una auténtica revolución del sector agrario insular. Ámbitos como la Geria, una antigua vaguada colindante a Timanfaya, quedan cubiertos por espesores de más de tres metros de lapilli - también conocido como rofe o picón en Canarias -, convirtiendo los antiguos y fértiles terrenos de cultivo en una superficie negra e inerte, al menos en apariencia. Los campesinos conciben una nueva técnica artesanal ya esbozada desde antaño en la zona norte de la isla, el enarenado natural, por la cual las cenizas que el volcán expulsa son reutilizadas en su propio beneficio para el cultivo. Olivia Stone señala:

\footnotetext{
"Nos sorprendió ver arena negra constantemente esparcida sobre el terreno. Sim embargo, aparentemente esta arena volcánica retiene mejor la bumedad (...). Hay bigueras en los hoyos, con muros alrededor para protegerlas del viento."
}

Ingenian un sistema en el que se excavan hoyos o socos en aquellas zonas recubiertas por las cenizas hasta alcanzar el sustrato fértil donde se cultiva, principalmente, la vid. Una vez se recubre con picón, se protege el conjunto del viento a través de muros de piedra seca semicirculares. La profundidad de la capa de lapilli determina la medida de los hoyos, llegando a alcanzar, en ciertos lugares, más de cuatro metros. La forma siempre es la misma, un cono volcánico invertido con una sección que permite que el lapilli permanezca estable y permita el fácil el acceso a las cepas plantadas en su interior. Da lugar, como fácilmente se deduce, a socos de medidas y profundidades muy distintas, produciendo una enorme variedad formal según zonas.

\footnotetext{
5 Arteta (2008)
} 


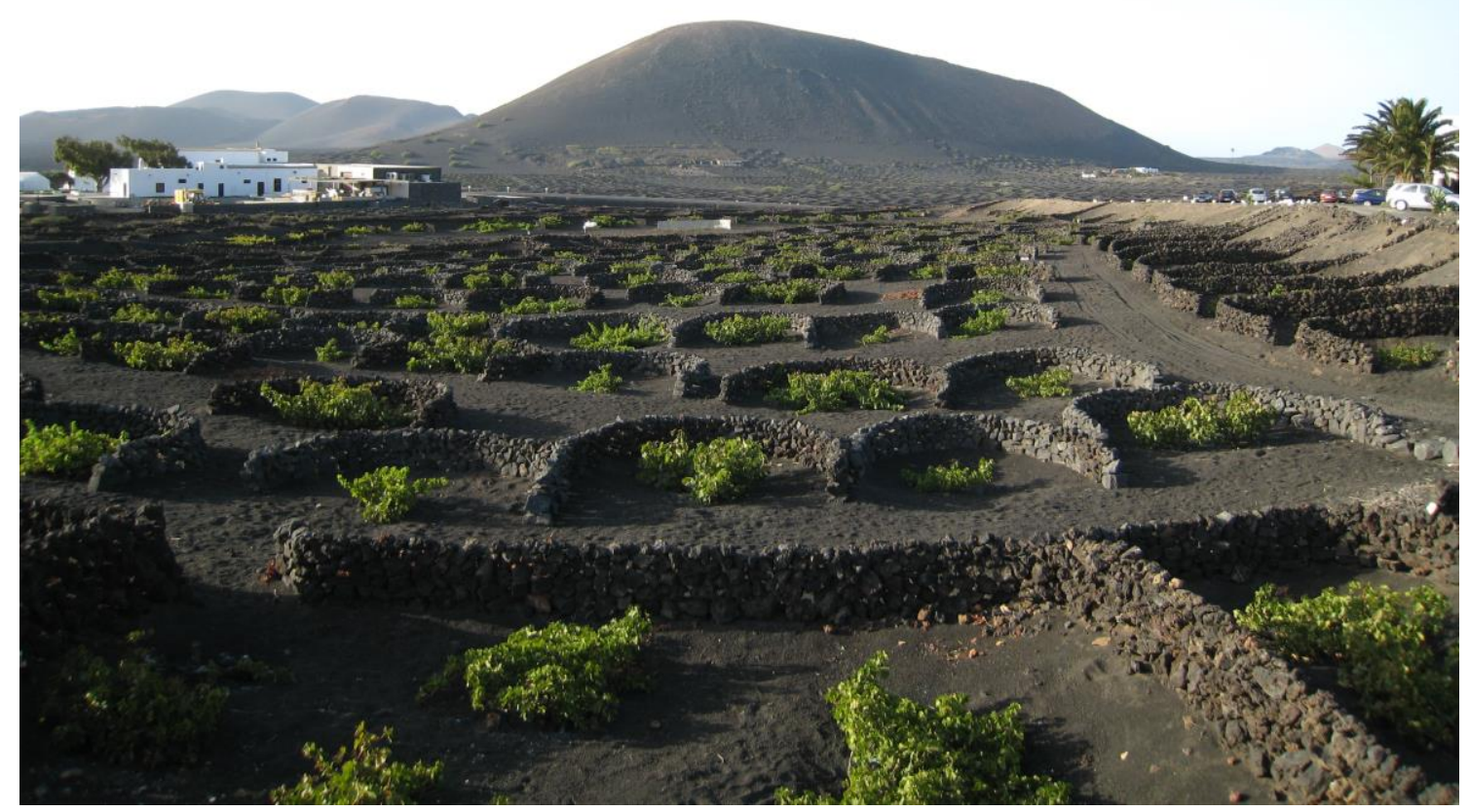

Fig. 5. Vista de la Geria (Autor: Antonio Zamora)

El murete de piedras acumuladas en el borde superior perfila el cono y confirma su circularidad. Apenas alcanza más de medio metro. Nunca se cierra, impediría el paso, a veces, es sólo medio círculo. Su función es proteger las cepas plantadas del viento perenne de los Alisios y recoger y ordenar el material sobrante de la propia excavación. Su efecto formal y visual es indudable, tanto como el funcional porque transfiere a la superficie las condiciones materiales de cada campo en medidas y disposición. Al estar construidos sólo con materiales obtenidos en la correspondiente excavación, la coherencia formal y cromática está garantizada. Además, la exposición al viento y al sol confieren al murete un color más claro que le diferencian del suelo, siempre oscuro, procedente del manto de lapilli que recubre todo, con las cepas como único motivo de verdor.

Dicho esto, parece que no hay en la Geria dos hoyos iguales pero no es así, se agrupan por familias, por zonas, por fincas. Cada una depende de la profundidad de la capa de las cenizas volcánicas, de la dirección del viento, de la pendiente del suelo, de las rocas en proporción y medida extraídas de la excavación o de la propia técnica utilizada. Tienen, en efecto, distinta medida y disposición, pero todos los hoyos se parecen en su forma, uso y condición. Sobretodo, constituyen agrupados, a centenares, a millares, estructuras de paisaje, completas, fragmentarias, pero, a la vez, unitarias con una extraordinaria capacidad de síntesis y de relación.

Un campo se diferencia de otro, no en sus límites, si no en la disposición de sus socos. Todos están hechos con los mismos materiales, únicamente cambian los sofisticados marcos de plantación. Algunas veces también, en las variedades de la cepa, casi siempre de uva blanca, la malvasía. Los viñedos, así plantados, construyen el paisaje de la Geria. Un mar ondulado de más de 2000 has entre Tías, Masdache y Yaiza, con densidades mínimas de no más de 2000 cepas por ha. - y que en ocasiones apenas alcanzan las 200 - y productividades muy bajas, menos de $1500 \mathrm{~kg}$ de uva por ha., que a su vez proporcionan caldos delicados, intensos y de notable valor (Álvarez, 1993). 
Interesa resaltar también la selección y el acierto en el uso adecuado para cada material. Del lapilli volcánico, se saca partido de su capacidad hidroscópica y de la escasa intolerancia a la germinación -se evitan, así, malas hierbas, y su consiguiente control. También, se evalúa y aprecia de las cenizas volcánicas su estabilidad y maleabilidad. De las rocas, se aprovecha su capacidad de constituir un soporte autónomo y resistir al viento. De la forma del cono volcánico construido, que provoca gran superficie de desarrollo, se persigue la capacidad de captación de la veladura de rocío que se adhiere a la ceniza y se transfiere a sus capas inferiores, es decir, su capacidad de auto irrigación.

La Geria es el máximo exponente del enarenado natural y de la arquitectura agrícola insular. Aún existiendo precedentes, su éxito se generaliza al conjunto insular tras las erupciones de Timanfaya a través del "enarenado artificial", una técnica que traslada los beneficios del lapilli en otro tipo de terrenos que, aún siendo fértiles, tienen una escasa producción. Así, extienden los campos de La Geria más allá de sus confines, generando un pintoresco mosaico agrícola en negro que se extiende por gran parte del territorio insular. Una variante sobre el tema se produce en el ámbito del "Jable". Dicho término, procedente del francés "sable", aprovecha las cualidades similares al picón de las arenas organógenas depositadas en la zona central de la isla, en el corredor que va desde Famara hasta Tías, para el cultivo fundamentalmente de sandías, calabazas, melones y batatas. Solventan así las carencias de un suelo, tan poco profundo como complejo y con escasa capacidad de irrigación.

\section{Conclusiones}

Nos gustaría entender la Geria de Lanzarote, en relación a tantos otros sistemas de formación y consecución de suelos aptos para la plantación construidos por la mano del hombre. Quizá aquí, a diferencia de tantos otros lugares donde el agua si no es abundante al menos es asequible, el medio es tan vaporoso y etéreo que no admite ni acumulación ni transporte, sólo precisísima gestión. El resultado es notorio y evidente: conseguir, gracias a la especial geología y climatología del contexto, un sistema hidrológico tan sutil e inteligente como extremo y eficaz.

La Geria es uno de esos paisajes donde el hombre y su obra se muestran en completa armonía con el entorno. Al igual que en su arquitectura vernácula, en sus labores agrícolas podemos hallar estas trazas que permiten mostrar cómo el hombre supo asimilar las particularidades de su entorno para intervenir en ellos. Con su proceder, genera paisajes antropizados donde dialogan naturaleza y cultura en beneficio de ambos. De esta forma, contribuye a crear espacios que subrayan el carácter emocional de la isla al tiempo que disipan la menor energía posible al construirlos y los nutren de identidad.

Es fruto de la dura lucha del campesino para sobrevivir en un medio tan hostil como el de Lanzarote, y el resultado es uno de los espacios agrarios más espectaculares de Canarias cuya estética de formas y colores ha devenido en uno de los principales reclamos turísticos de Lanzarote. La elevada carga estética de su paisaje han llevado a compararlo con el land art. Hoy, sin embargo, el deterioro de la actividad agrícola junto al auge del turismo pone en entredicho su posición, produciéndose un creciente abandono de la agricultura que afecta no sólo a la Geria sino al conjunto del paisaje agrario insular. 


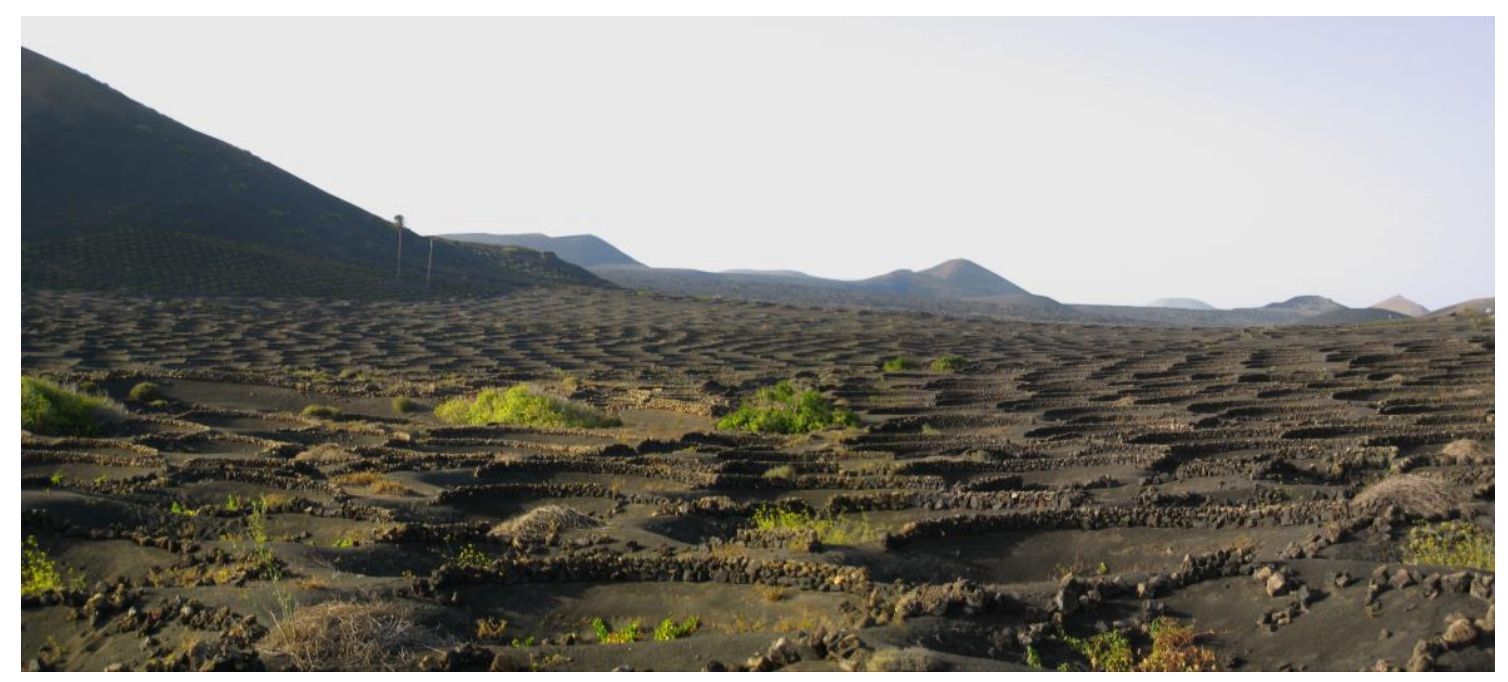

Fig. 6. Panorámica de la Geria (Autor: Antonio Zamora)

\section{Referencias}

AA.VV. (1995): José Ramírez y César Manrique. El Cabildo y Lanzarote, una isla como tema, Servicio de Publicaciones del Cabildo de Lanzarote, Bilbao.

AA.VV. (2005): El turista interminable. Francesc Catalá-Roca y Nicolás Muller en Canarias, Gobierno de Canarias, San Nicolás de Tolentino.

AA.VV. (2006): La cultura del agua en Lanzarote, Gobierno de Canarias y Cabildo de Lanzarote, La Laguna (Tenerife).

Álvarez Alonso, A. (1993): Los paisajes agrarios, en Geografía de Canarias, Prensa Ibérica, pp. 309-324.

Arteta Viotti, A. (2008): "Visiones plásticas y literarias del paisaje lanzaroteño en el mundo contemporáneo. Notas para su estudio" en AA.VV., XII Jornadas de estudios sobre Lanzarote y Fuerteventura. Tomo II, Cabildo insular de Lanzarote y Cabilldo insular de Fuerteventura, pp. 31-60, Arrecife, 2008.

De Santa Ana (ED), M. (2004): Paisajes del placer, paisajes de la crisis, Fundación César Manrique, Teguise.

Dematteis, G. (1995): Progetto implicito. Il contributo della geografia umana alle scienze del territorio, FrancoAngeli, Milano.

Espinosa, A. (1988): Lancelot, $28^{\circ}-7^{\circ}$. Guia integral de una isla atlántica, Interinsular canaria, Santa Cruz de Tenerife.

Fernández Lavandera, O. y Pizarro, A. (1982): La agricultura en las Islas Canarias, Revista de Estudios Agrosociales, 119:8-34.

Galí-Izard, T. (2005): Los mismos paisajes. Ideas e interpretaciones, Gustavo Gili, Barcelona.

González Morales, A. (2007): Lanzarote y el agua. Un recurso vital y estratégico, Cabildo de Lanzarote, S.C.R.D. Torrelavga, Inalsa y Gobierno de Canarias, Arrecife.

Maderuelo, J. (2006): Jameos del Agua, Fundación César Manrique, Teguise.

Manrique, C. (1991): Escrito en el fuego, Edirca, Las Palmas de Gran Canaria. 
Manrique, C. (1974): Lanzarote, arquitectura inédita, Cabildo de Lanzarote, Arrecife.

Martínez, C. (1936): "Motivos turísticos de Lanzarote. Las Montañas del Fuego. Timanfaya”, Lanzarote Turístico, Arrecife.

Santana, L. (1997): Timanfaya, Fundación César Manrique, Teguise.

Saramago, J. (1997): Cuadernos de Lanzarote (1993-1995), Alfaguara, Madrid.

Sardà, J. (2012): Lecturas comparades. La conquista de la natura versus la terra plantada, en Sardá, J., Només imatges. La targeta postal, vehicle de coneixement urbà, tesis doctoral. Universitat Politècnica de Catalunya, Barcelona.

Sabaté, F., Sabaté, J. y Zamora, A. (2013): César Manrique: la conciencia del paisaje, en Sabaté, J. (ed.), César Manrique. La conciencia del paisaje, Gráficas Sabater, Santa Cruz de Tenerife.

Turri, E. (2004): Il paesaggio e il silenzio, Marzilio Editore, Venezia.

Zamora, A. (2009): La artealización de Lanzarote, tesina del Master de Paisaje. Universitat Politècnica de Catalunya (www.memoriadigitaldelanzarote.com), Barcelona.

Zamora, A. (2012): La propuesta implícita. Paisaje, arte y turismo en la construcción territorial de Lanzarote (1960-74), tesina del Master de investigación en Urbanismo. Universitat Politècnica de Catalunya, Barcelona (mimeo). 